\title{
Two SORTS OF CONSTITUTIVISM
}

\author{
Jeremy David Fix \\ Forthcoming in Analytic Philosophy \\ Penultimate draft. Please cite the published version.
}

Abstract: Some things, but only some things, are by nature subject to standards. Why? I explain a constitutivist answer to this question in terms of certain genera possessing essential properties which their particulars can possess or lack. When something is by nature subject to a standard, it is so subject because it is a particular of a genus with such properties, and it is subject to a standard with respect to those very properties. I then explain the account of the nature and structure of normativity which follows.

\section{Directions of dependence}

1.1 Some things, like our hearts, actions, and socks, are by nature subject to standards. Others, like rocks and squares, are not. Why? What explains this difference between the animate with their artifacts and the rest of the inanimate stuff in the world? According to constitutivism, the answer is a unique relationship between metaphysics and normativity:

Something is a particular of genus $G$ if and only if it is subject to standard $N .{ }^{1}$

That biconditional, though, just says that some things are by nature subject to standards. It cannot explain why. The simplest fix is to turn it into a metaphysical explanation:

Nature-First Something is subject to standard $N$ because it is a particular of genus $G$.

Norms-First Something is a particular of genus $G$ because it is subject to standard $N$.

One says that what something is determines what it should be, the other that what it should be determines what it is. So long as 'because' is univocal in them, they are incompatible. ${ }^{2}$

Although each view grounds the biconditional, only the nature-first one is fit for purpose. Consider that Douglas Lavin claims that constitutivism is "the main alternative to platonism among nonreductive and realist accounts of" normativity (Lavin [2004] 429; original emphasis). Its "basic attraction" is the promise of a "metaphysics of normativity that would make the nature and authority of these norms ... transparent" (Lavin [2017] 192). Christine Korsgaard says that platonism lacks that promise because it "points with premature

1. I use 'genus' and 'particular' to designate a metaphysical contrast which can hold in between a kind and its members, a type and its tokens, a capacity and its exercises, an activity and its instances, and so on.

2. What if 'because' has different senses in these propositions? The obvious difference is between explanatory and epistemic senses in the way that there is smoke because there is fire picks out an explanatory relationship, there is fire because there is smoke an epistemic one. That distinction, though, just generates versions of the nature and norms first views depending on which proposition is construed as an explanation. 
satisfaction at the place where the explanation must go" by simply positing standards (Korsgaard [2009] 6). Since the norms-first view invokes standards in order to explain things but does not explain those standards, they can be platonic. ${ }^{3}$ That is why Lavin, Korsgaard, and others opt for the nature-first view:

standards ... apply to a thing simply in virtue of its being the kind of thing that it is.

(Korsgaard [2009] 28)

the grounds of these unconditional oughts are to be found in the nature of agency.

(Ferrero [2009] 303-4)

the authority of certain normative claims arises from the bare fact that we are agents.

(Katsafanas [2013] 1)

basic practical requirements are grounded in the nature of action.

(Lavin [2017] 172)

The fundamental norms that apply to $\mathrm{X}$ are explained by the nature of $\mathrm{X}$.

(Schafer [2019] 77)

constitutive norms of agency ... arise from the nature of agency as such.

(Tenenbaum [2019] 163-4)

Whether the nature-first view can explain why only certain things are by nature subject to standards, though, depends on what distinguishes genera whose particulars are so subject from those whose particulars are not. If something is subject to a standard because it is a particular of a certain genus and if only particulars of certain genera are by nature subject to standards, something must unify those genera and distinguish them from others. Animate and artificial genera must have a distinctive type of nature. What distinguishes it, and why are particulars of those genera thereby subject to certain standards? That is the central question of this essay.

1.2 I shall argue that the key to the answer is to reject a nearly universal assumption about the nature of essential properties:

Necessitarianism All essential properties of all genera are such that particulars of those genera must possess those properties.

3. You can combine the norms-first view with a non-platonic account of normativity, but the constitutivism does not do any of that explanatory work. 
For example, equilaterality is an essential property of the genus SQUARE. It is part of the answer to the question 'What are squares?' or 'What is the square?' And every square must possess it. Necessitarianism says that all essential properties are like that. I will argue instead that some essential properties of some genera are such that particulars of those genera can possess or lack those properties. For example, having two legs is an essential property of the genus HUMAN BEING. It is part of the answer to the question 'What are human beings?' or 'What is the human being?' Yet human beings can lack legs.

I shall claim that possessing such essential properties distinguishes genera whose particulars are by nature subject to standards from those whose particulars are not. I will also claim that particulars are by nature subject to standards with respect to those essential properties of their genus. Something is subject to a specific standard, then, because it is a particular of a genus which possesses specific essential properties which its particulars can possess or lack. That is the answer to the central question of this essay.

In more detail, I will first show that necessitarianism lies behind a common objection to constitutivism. I shall then defend the possibility and the actuality of a type of essential property which contradicts necessitarianism. I will then argue that those essential properties of genera are the good-making properties for particulars of those genera. I shall finally explain the account of normativity which follows from this account of the grounds of normative properties.

1.3 Two caveats before I begin. First, constitutivists contrast internal standards to which something is by nature subject with external ones to which something is subject but not by nature. An internal standard for a bed is its suitability for sleeping, an external one its suitability for trampolining. Nature-first constitutivism must first explain the nature of internal standards and then ground external ones in internal ones. My primary concern is that first step. I discuss external standards only at the end of the essay.

Second, most discussions of constitutivism, critical or constructive, zip past questions about the explanatory structure of the view and zero in on questions about our agency. ${ }^{4}$ Those questions, though, are about the application of the metaphysics to a specific case. My task is thus preliminary to asking and answering them. I shall only explain the metaphysics of

4. See (Korsgaard [2009]) for a Kantian account, (Katsafanas [2013] for a Nietzschean account, (Smith [2013]) for a Humean account, and (Velleman [2009]) for an account somewhere between Humean and Kantian. See (Enoch [2006]; [2011]) for the most common doubt about the possibility of any such account of our agency. See (Ferrero [2009]) for a response, and consider the discussion in (Lavin [2017] 186-9). 
nature first constitutivism. Its applications and vindication must wait for another occasion.

\section{The possibility of contingent essential properties}

In this section, I show that necessitarianism lies behind a common objection to constitutivism and then defend the possibility of properties which contradict it. In the next, I defend the actuality of those properties.

2.1 When nature-first constitutivists say that something is subject to a standard because it is a particular of a genus, they do not think that the content of the standard and the nature of the genus have nothing in common. In the formal mode, the claim is that (some of) the properties which feature in an account of the genus also feature in the standard for particulars of that genus. In the material mode, the claim is that (some of) the essential properties of the genus are good-making properties of particulars of that genus. Only with this connection between the genus and standard for its particulars is the "nature and authority of that standard transparent', or so the thought goes. ${ }^{5}$ The claim is thus that a particular is good to the extent that and because it possesses certain essential properties of its genus, bad to the extent that and because it lacks them.

That claim is puzzling if you assume necessitarianism. The problem of bad action says that the puzzle is insoluble. ${ }^{6}$ It has the form of an inconsistent triad of propositions. The first one says that the possibility of error conditions normativity. ${ }^{7}$

If $F$ is a good-making property for particulars of $G$, particulars of $G$ can lack $F$.

The second says that good-making properties of particulars are essential properties of genera.

If $F$ is a good-making property for particulars of $G, F$ is an essential property of $G$.

The third is the necessitarian claim about essential properties.

5. Korsgaard puts this point by saying that "every object and activity is defined by certain standards that are both constitutive of it and normative for it" (Korsgaard [2009] 32). It is unclear whether this is her view or is instead a Platonic view which she would qualify. Regardless, the universal quantification is an error. The link between the the nature of the genus and the content of the standard, though, is why these standards "meet skeptical challenges to their authority with ease" (ibid. 29).

6. The problem is ill named because it does not turn on anything unique to action. For discussion, see, among others, (Korsgaard [2009] 159-76), (Kastafanas [2013] 61-5), and (Pauer-Studer [2018]).

7. See (Korsgaard [1998]) and (Lavin [2004]) for discussion of the significance of the error condition in action theory. I criticize their interpretations of this condition and offer an alternative in 'The Error Condition'. 
If $F$ is an essential property of $G$, particulars of $G$ must possess $F$.

Since particulars of $G$ cannot possibly lack and necessarily possess $F$, these propositions are inconsistent. The first is undeniable. To reject the second is to abandon nature-first constitutivism. The third proposition and thus necessitarianism must go.

2.2 I will defend the conceptual possibility of essential properties of genera which particulars can lack. I start with definitions which ease exposition. Say that an essential property of a genus is part of the nature of that genus. It features in an account of that genus and is part of the answer to the question 'What are Gs?' or 'What is the G?' Say that a necessary property of a genus is one that every particular of a genus must possess. Necessitarianism then says that all essential properties of all genera are necessary properties of them.

Nature-first constitutivism says otherwise. To understand how, articulate the complements of necessary and essential properties. Necessary properties contrast with contingent ones. Whereas particulars of a genus must possess any necessary property of it, they can possess or lack contingent properties of it. For example, with respect to squares, equilaterality is a necessary property, having $4 \mathrm{~cm}$ sides a contingent one. Essential properties contrast with accidental ones. An essential property of a genus is part of the nature of the genus. It features in an account of that genus. An accidental property of a genus is not and does not, though particulars can possess it. ${ }^{8}$ For example, with respect to squares, equilaterality is an essential property, having $4 \mathrm{~cm}$ sides an accidental one.

To link essential properties of genera with necessary properties of them is a substantive metaphysical thesis because the necessary/contingent and essential/accidental distinctions crosscut. They allow for a fourfold distinction of such properties:

(1) Necessary essential properties which are part of the nature of a genus and which every particular of that genus must possess.

(2) Necessary accidental properties which are not part of the nature of a genus and which every particular of that genus must possess.

(3) Contingent essential properties which are part of the nature of a genus and which particulars of that genus can possess or lack.

(4) Contingent accidental properties which are not part of the nature of a genus and

8. These definitions exclude properties which particulars of a genus cannot possess. A number can be neither soft nor hard, a square neither warm nor cold, a human being neither odd nor even, and so on. These properties are neither necessary nor contingent, neither essential nor accidental, properties of those genera. 
which particulars of that genus can possess or lack.

Necessitarianism denies the possibility of contingent essential properties. Are they possible? ${ }^{9}$

One way to get a grip on that question is to compare it with one about necessary accidental properties. Take human beings. All of us can go up in flames. Flammability is a necessary property of the human being. Is it thereby part of what it is to be a human being and thus an essential rather than accidental property of the human being? Perhaps not. Maybe it is grounded in but not part of our essence. If so, flammability is not an essential property of the human being even though it is a necessary property of that genus. It is not part of the answer to the question 'What is the human being?' even though all of us can burn. Agree and you think that there are necessary accidental properties. Or you can disagree about this and every other necessary property. Whichever way you go, though, you need an argument because necessary accidental properties are conceptually possible. ${ }^{10}$

The question about the possibility of contingent essential properties has the same structure. Answers to it have the same status. Take human beings again. Some of us lack two legs. Having two legs is a contingent property of the human being. Is it thereby not part of what it is to be a human being and thus an accidental rather than essential property of the human being? Perhaps not. Maybe it is part of our essence. If so, having two legs is an essential property of the human being even though it is a contingent property of that genus. It is part of the answer to the question 'What is the human being?' even if I lose a leg in a round of Twister. Agree and you think that there are contingent essential properties. Or you can disagree about this and every other contingent property. Whichever way you go, though, you need an argument because contingent essential properties are conceptually possible.

There is thus no conceptual connection between necessity and essence. Possibly, there are necessary properties of a genus which are accidental rather than essential properties of it. Possibly, there are essential properties of a genus which are contingent rather than necessary properties of it. Necessitarianism cannot be assumed without argument or acknowledgment.

9. This fourfold distinction is not exhaustive of properties of genera. In particular, it ignores properties which mark the generality of a genus. The genus HUMAN BEING is essentially such as to have more than one bearer, the genus KNIFE is essentially such as to have more than one token, and so on for all genera. That is part of what it is for something to be a genus. Since particulars cannot possess this property, it is neither a necessary nor a contingent property of genera in the senses under discussion. Since these properties of genera do not matter for my purposes in this essay, though, I will ignore them.

10. See Kit Fine [1994; 1995a; 1995b]. Although he does not explain essence in terms of necessity, Fine says that a "property of an object is essential if it must have the property to be what it is" (Fine [1995a] 53). Having two legs is then not an essential property of mine. It thereby is not an essential property of the human being. On this view, then, all essential properties of all genera are necessary properties of them even though not all necessary properties of all genera are essential properties of them. For a similar argument, see (Boyle [2012] §2.4). 


\section{The Actuality of Contingent Essential Properties}

Conceptual possibility often comes cheap, and example-mongering might convince only the choir about whether there are any contingent essential properties. In this section, I often a philosophical ground for those examples by showing that the contingent properties mentioned in them have the explanatory profile of essential properties. There are two questions to answer. What is that profile? Do any contingent properties have it? I take up these questions in turn.

3.1 I here present a traditional view about the relationship between essence and explanation. Put in terms of metaphysical dependence, the view is that everything which is not an essential property metaphysically depends on essential properties but those properties do not metaphysical depend on anything. Put in terms of metaphysical explanation, the view is that metaphysical explanations terminate in essential properties. For any legitimate question 'Why?' which asks for a metaphysical explanation, its ultimate answer is in terms of essential properties. Yet since essential properties terminate such explanations, they are not subject to requests for explanation. I cannot establish this account of the explanatory profile of essential properties, but I will here explain and employ it,

Analogies with formal proof systems help. On this view, "essentialist truths are the worldly analogue of nominal definitions [and] stand to ground as nominal definitions do to proof: the question of what grounds them strikes us as illegitimate in something like the way that the question of how one might prove a definition does" (Dasgupta [2016] 386). As definitions are the proper basis for any proof within a system, so essential properties are the proper basis for any metaphysical explanation. As definitions need no proof within that system, so essential properties need no metaphysical explanation. This is because what "is used to prove everything else, cannot itself be proved: a chain of proofs must have their commencement somewhere. To give such a proof is as impossible as it is needless" (Bentham [1789] I.11). A 'proof' of a nominal definition is 'impossible' because those definitions constitute the standards of proof in that system. It is 'needless' because their role in that system is to be the basis of proofs, not the subject of proofs. The legitimacy of their playing that role does not depend on their being proven. It depends on their being stipulated. Similarly, the traditional view is that a metaphysical explanation of an essential property is impossible because these properties constitute the standards of such explanation. It is needless because the legitimacy of their role in that system is to be the basis of explanation, 
not the subject of it. The legitimacy of their playing that role does not depend on their being explained. It depends on their being the case-on their being essential properties of somethings.

The explanatory profile of an essential property, then, is, in the formal mode, to metaphysically explain other things but not to be so explained. It is, in the material mode, to metaphysically ground other things but to not metaphysically depend on anything.

One way to understand this profile is to use it to test whether something is an essential property. Think about necessary accidental properties. Take our solubility in potassium hydroxide, as necessary a property of the human being as our flammability. According to this view of the relationship between essence and explanation, this solubility is an accidental property of the human being because it depends on our essential properties and the essential properties of potassium hydroxide. The chemical properties of human matter and of potassium hydroxide explain our solubility in it. Hence, the question 'Why are human beings soluble in potassium hydroxide?', when heard in the proper metaphysical register, has an answer. In contrast, our consisting of human matter does not metaphysically depend on anything, nor does the chemical composition of potassium hydroxide. To the question 'Why are human beings made up of this type of matter?', when heard in the proper metaphysical register, the only thing to say is 'That just is what human beings (in part) are'. That response neither answers nor despairs of answering the question. It instead denies the legitimacy of this request for metaphysical explanation. So it is as well with respect to the question "Why does potassium hydroxide have chemical composition $\mathrm{KOH}$ ?'

Whereas that question is about whether any necessary properties of genera lack the profile of essential properties, the question about contingent essential properties is whether any contingent properties possess that profile. So first, are there contingent properties which explain or ground? Second, are any of these properties exempt from explanation? Are they metaphysically independent in the relevant sense? I take up these questions in turn.

3.2 Consider what it is for something to lack a property. Lacking requires more than not possessing the property. If my cat and I each have two legs, only one of us lacks the property of having four even though neither of us possesses it. Only one of us is missing two legs. Why? Similarly, although I might see as little as a rock, only one of us is blind. Why?

Aristotle claims that "a thing suffers privation when it has not an attribute in those circumstances, or in that respect and in that relation and in that sense, in which it would naturally have it" (Aristotle Metaphysics $\Delta$ 1022 $22-1022_{b} 32$ ). In my language, a particular 
lacks or is missing a property when that property is a contingent essential property of its genus. Having four legs is a contingent essential property of the genus CAT but not the genus HUMAN BEING. That is why my cat lacks legs when I do not even though we each have two legs. It is also why he lacks legs but not the color black even though he is neither black nor four-legged. Although having four legs and being black are each contingent properties of his genus, only the former is an essential property of it. Similarly, sight is a contingent essential property of the genus HUMAN BEING but not the genus ROCK. I am thus blind whereas a rock is not even though neither of us can see. In general, then, something lacks a property when it is a particular of a genus of which that property is an essential property and yet it does not have that property. To lack a property is to not possess a contingent essential property.

Although the possibility of privation is not much on the scene these days, Aristotle builds it into his metaphysics from the get-go. While discussing real definitions, he asks "wherein consists the unity of that, the formula of which we call a definition, as for instance in the case of man, two-footed animal" (Aristotle Metaphysics Z 12 1037b9-12). ." Yet he knows that humans can lack some of their parts. After all, he famously says that certain parts "cannot even exist if severed from the whole: it is not a finger in any state that is the finger of a living thing, but the dead finger is a finger only homonymously" (Aristotle Metaphysics Z 10 1035b22-5). Still, although the finger is one only homonymously, the human being is not one only homonymously. The finger is no more. The human remains. As with fingers, so with legs and feet even though I, human being and thus bipedal animal, might tell tales of Twister games of old while polishing my peg-leg. Hence, particulars can lack certain properties which are part of the account of the genus. These properties of genera are part of the account of why a particular of that genus without a property lacks it while a particular of a different genus without that same property does not lack it. They thus ground and explain things in the way in which essential properties do.

3.3 The second aspect of the profile of essential properties is that they are not subject to metaphysical explanation or that they do not metaphysically depend on anything. This aspect falls out of the previous one. If essence stands to explanation in the way in which nominal definition stands to proof, something is explained in terms of essential properties in the way that something is proven from these definitions. Essence in this way constitutes what counts as metaphysical explanation in the way that definitions constitute what counts as a proof in

11. Despite renewed interest in real definition, the fact that some of Aristotle's examples defy necessitarian constraints goes unnoticed. See, for example, (Rosen [2015]) and (Dorr [2016]) for accounts of real definition which assume necessitarianism without argument or acknowledgment. 
that system. If essence so determines explanation, though, a request to explain essence must be illegitimate because any explanation presupposes that whose explanation is requested.

Try it this way. Any view of the essence of something must include some properties, and requests for explanation must be inapt with respect to some of them. Imagine if they were not. Some property must explain why those properties are essential properties of the genus. What is the status of that property? If it is an essential property of the genus, it is subject to the same request. That way a regress lies. If it is not, it is either an accidental property of the genus or it is not a property of the genus at all. Neither option works. The fact that some human beings have red hair or that we are flammable cannot explain why we are animals or why we are bipedal. Neither can the essence of water.

The question is whether any contingent properties have this profile. Yet to the extent that requests to metaphysically explain certain necessary properties are illegitimate, requests to explain certain contingent properties are as well. Take the claim that the human being is a bipedal animal. Is the question 'Why are human beings animals?' less legitimate than the question 'Why are human beings bipedal?' when each is heard in a metaphysical key? To each, the only things to say is 'That just is what the human being is'. Yet one property is a necessary, the other a contingent, property of the genus.

The illegitimacy of these questions falls out of a traditional view of organisms which constitutivists invoke. ${ }^{12}$ Kant claims that with respect to an organism, "the possibility of its parts (as concerns both their existence and their form) must depend on their relation to the whole. ... [And] the parts of the thing combine into the unity of a whole because they are reciprocally causes and effect of their form" (Kant [1790] 5:373). On this view, accounts of the living being in terms of its parts go round in a circle because the only way to understand the whole is in terms of the parts but the only way to understand the parts is in terms of the whole. As I prefer to put it, an account of the essence of an organism in terms of its parts and its characteristic activities elucidates the nature of the organism. It does not explicate that nature into something more fundamental.

For example, to say that the human being is bipedal is to make claims about our number of legs and about one of our characteristic ways of moving. Yet the content of each of these claims in the end referes back to the human being. To say that the human being has two

12. In the first part of Life and Action, Thompson argues that any non-circular account of life is impossible. Invoke something which does not mention life or vital processes and you get the extension wrong. Invoke something which gets the extension right and you invoke something which mentions life or vital processes. My argument here is that any non-circular account of a kind of organism is impossible on similar grounds. Invoke something which does not mention that type of organism and you get the extension wrong. Invoke something which gets the extension right and you invoke something which mentions that type of organism. 
legs is sometimes useful, but it does not explain the human being into more fundamental properties. After all, not just any legs will do. A human being with something which resembles the front left leg of an alligator and something which resembles the right leg of a chicken lacks the property predicated in 'Human beings have two legs' just as much as a human being with no legs. A human being has two human legs-that is the property which partially elucidates the nature of the genus. Hence, "living things are made of parts that strictly speaking cannot exist independently of the living things themselves" (Korsgaard [2008] 36).

Similarly, human beings walk, and perhaps it is sometimes helpful to say that our capacity to walk is in part a capacity to move by putting one foot in front of the other while maintaining balance. To say it, though, is not to presuppose that the elements of 'move by putting one foot in front of the other while maintaining balance' are more fundamental than 'walk'. After all, not just any way of putting one foot in front of the other will do. I am not walking if I sequentially impale my feet with an ice pick and swing them forward no matter of how well I line them up one in front of the other and keep my balance. I am only walking if I move them in a specific way-walkingly, as we might joke. Yet the way that a human being walks is very different than the way that a cat walks in virtue of the different number and structure of our legs. Hence, to say that to walk is in part to put one foot in front of the other while maintaining balance is to elucidate things when needed, not to explicate walking into more basic elements. To say that the human being is bipedal is thus to move horizontally, not vertically, in the explanatory order, to elucidate, not explicate.

Hence, being "a human being is ... an irreducible property of the individual that bears it: we cannot say what it is to be a human being by specifying other more basic features individuals might have that would make them human beings" (Boyle [2012] 403). This is not because there are no properties which specify human nature but because accounts of those properties are inextricably tied up with the account of our nature. In this way, some contingent properties have the second aspect of the profile of essential properties. There is no metaphysical explanation of them and they do not metaphysically depend on anything else.

Reflecting on this tradition, Matthew Boyle says that "predicates that appear in a definition of a certain substantial kind ... stat[e], not features that individuals must have if they are to belong to that kind, but rather attributes that directly characterize the nature of the substantial kind itself" (ibid. 405). These "propositions about the essential features ... are propositions about the kind ... and there is no immediate inference to be drawn from such truths to freestanding propositions about what particular individuals of the kind are like" 
(ibid. 408). There are thus "exceptions which do not disprove the rule" (ibid.). As stated, those claims are false because too broad. 'The human being is material' or 'The human being is finite' are as much about our essence as 'The human being is bipedal'. ${ }^{13}$ Immediate inferences from the first two claims to propositions about particular human beings are felicitous. No gaps or exceptions. Immediate inferences from the latter claim to propositions about particular human beings are infelicitous. Gaps present. Exceptions allowed. Whether a claim about the essence of a genus licenses inferences to the particulars of the genus, then, depends on whether it is about a necessary essential property or a contingent essential property. Still, suitably qualified, Boyle is right that some properties which feature in the accounts of some genera are not properties which particulars must possess but are instead properties which particulars can possess or lack. That is to say that some essential properties of some genera are contingent properties of those genera. ${ }^{14}$

\section{The Scope of Standards}

The central question of this essay has two parts. The first is about what distinguishes genera whose particulars are by nature subject to standards from genera whose particulars are not. The second is about how that distinguishing mark explains why those particulars are subject to specific standards. In this section, I argue that contingent essential properties answer both parts of this question.

3.1 Most constitutivists think that the animate and their artifacts are by nature subject to standards while the inanimate are not. Consider the list of things which Korsgaard says are by nature subject to standards: cheetahs, tigers, antelope, knives, encyclopedias, cars, hotel

13. Genericity, as a feature of sentences, is thus not enough to pick out contingent essential properties. As Michael Thompson puts it, although the relevant judgments "can be expressed in a 'generic' sentence[,] ... the class of generic sentences" with a bare plural subject "is ... a ragbag covering many forms of conjunction of subject and predicate" just as the "similarly identified class of "statements with a definite description as subject" is "a merely surface-grammatical category" (Thompson [2008] 69; original emphasis). Sentences with such subjects can predicate any type of property of a genus. 'Humans are finite', 'Humans are flammable', 'Humans are bipedal', and 'Humans are competitive' have the same surface grammar and yet only the third exemplifies the relevant form of judgment. Likewise for versions of those sentences with definite descriptions as subject.

14. Given this discussion, Dasgupta might then seem like an odd ally since he endorses the claim that if "it is essential to $\mathrm{x}$ that $\phi$, then $\phi$ because it is essential to $\mathrm{x}$ that $\boldsymbol{\phi}$ ' (Dasgupta [2016] 387). Restrict this claim to necessary essential properties, though, and you can formulate a claim with respect to contingent essential properties which has the same logical form. To wit: 'if something is a necessary essential property of a genus, then a particular of that genus necessarily has that property because it is a particular of that genus' is compatible with 'if something is a contingent essential property of a genus, then a particular of that genus should have that property because it is a particular of that genus'. The only difference between these conditionals is the flavor of the modal operator-metaphysical necessity in the former, normative necessity in the latter. (To make this obvious, substitute 'must have' for 'necessarily has' and 'should have' and interpret it differently in each conditional.) The claims about necessary and contingent essential properties are thus different determinations of a determinable claim. Dasgupta need not reject anything in this section. 
rooms, airports, and grocery stores (Korsgaard [2019] 98). One must add the roots of trees and the budding of flowers and the various other parts and activities of plants which Philippa Foot and Michael Thompson bring under the category (Foot [2001]; Thompson [2008] §1). ${ }^{15}$ Notice what is not on this list: rocks, planets, dust, hydrogen, protons, and so on. Does possession of contingent essential properties track that division?

Think about artifacts such as eyeglasses. Any account of this genus must mention intact lenses and mechanisms to keep them in front of their eyes of their wearer. Why? Because we create artifacts for purposes, for use in the exercise of certain of our capacities. The nature of an artificial kind is what a token needs in order to serve that purpose in its characteristic way. Glasses have clear lenses, something that lets them sit in front of our eyes, and other things so as to improve the vision of their intended wearer. Those properties are thus essential properties of the genus which are part of the answer to the question 'What are eyeglasses?' Yet not every pair has them. Lenses fall out and get scratched, frames bend and break. Artificial kinds thus have contingent essential properties.

So do the animate. The earlier discussion of human beings shows that animals have contingent essential properties. We have parts-legs, feet, fingers, and so on-which members of the kind can lack, lose, or damage. The same basic explanatory structure, though, applies to the activities and capacities of the animate. For example, although I shall not offer an account of the nature of our capacity to act, it is at least in part a capacity to take sufficient means to an end. ${ }^{16}$ That is part of what it is for a finite being to act in the world. It is part of the answer to the question 'What is the human capacity to act?' or 'What is human action?' and is an essential property of our capacity to act. Yet exercises of this capacity can lack that property. Sometimes, I do not pull off my end because of interruption, interference, incompetence, or what have you. Taking sufficient means to an end is thus a contingent essential property of our capacity to act. ${ }^{17}$

Similarly, an account of the nature of feline or bovine digestion includes various

15. Korsgaard brings plants under this category in other work. See (Korsgaard [2018] 20).

16. I explain how to ground this standard in 'The Instrumental Rule'.

17. You can put this point in different terminology. For example, where I talk in terms of capacities, others talk in terms of activities. So, where I say that taking sufficient means is a contingent essential property of our capacity to act because it describes the nature of that capacity and yet exercises of that capacity can lack it, they must say that taking sufficient means is an essential property of human action as a type of activity which human actions as instances of that type of activity can lack. These differences are ideological, not ontological. I prefer capacity predication on grammatical grounds. While it must make explicit the genus/particular relationship at the heart of this explanation, activity predication can leave that relationship implicit. With capacity predication, you must use different terms for the genus and its particulars. You must use capacity to A for the genus and exercises of the capacity to $A$ for its particulars. With activity predication, things are different. You can use different terms for the genus and its particulars. You can use activity of A-ing for the genus and instances of A-ing for its particulars. However, you can also use A-ing for either the activity or the instances of that activity. That 
claims about the way that the animal in question consumes food, breaks it down, distributes the nutrients throughout the body, and disposes of waste. The properties there mentioned, such as swallowing, are part of what it is for the cat or the cow to digest. They are part of the answer to the question 'What is the feline/bovine capacity to digest?' or 'What is the feline/bovine digestion?' and are essential properties of those capacities. Yet exercises of those capacities can lack those properties. Animals choke, waste might not be disposed, and so on. Those properties are thus contingent essential properties of the relevant capacities to digest.

Inanimate natural stuff, in contrast, does not have such properties. The complete answer to 'What are squares?' is that they are equilateral, equiangular quadrilaterals. Anything without all of those properties is not a square. Similarly, the complete answer to 'What is a hydrogen atom?' is that it is an atom with one proton. Anything without that property is no such atom. All of the essential properties of these genera are necessary properties of them. The possession of contingent essential properties thus tracks the genera whose particulars are by nature subject to standards.

3.2 Can those essential properties explain why particulars of those genera are subject to specific standards? I shall here argue that particulars are subject to standards with respect to those very contingent essential properties of their genera. That is why the 'nature and authority of these standards is transparent'. I will explain the account of normativity which follows from this story in the next section.

Think again about eyeglasses. Even though having intact lenses is a contingent property of glasses, a pair without them is to that extent a bad pair. Why? Because we create artifacts for purposes, for use in the exercise of certain of our capacities. The nature of an artificial kind is what a token needs in order to serve that purpose in its characteristic way. When the lenses or frame of a particular pair fracture, that pair is thereby to that extent a bad pair of glasses. The goodness or badness of a pair of glasses thus depends on whether it has all, some, or none of the contingent essential properties of its genus and, if these properties come in degrees, to what degree it has them.

Think now about the human heart. The complete answer to the question 'What is the human heart?' mentions its four-chambers, their roles in our cardiovascular health, and so on. A human heart is good to the extent that and because it has these properties. It has four

temptation leads to formulations which obscure the explanatory structure of the view, as in Korsgaard's claim that "every object and activity is defined by certain standards that are both constitutive of it and normative for it" (Korsgaard [2009] 32). The obscurity is that the first 'it' refers to the genus, the second to the particulars, and yet because Korsgaard talks in terms activities, her language lets her obscure that distinction. 
chambers which are intact, with no blockages or holes which leak blood into the chest cavity, with sufficient strength to compress and circulate oxygenated blood without tearing, and so on. A human heart is bad to the extent that and because it lacks these properties. The goodness or badness of a human heart thus depends on whether it has all, some, or none of the contingent essential properties of its genus and, if these properties come in degrees, to what degree it has them. ${ }^{18}$

Again, our capacities and their exercises embody the same explanatory structure. Our capacity to walk is in part a capacity to put one foot in front of the other while maintaining balance. Yet sometimes we trip, slip, stumble, and tumble. Maintaining balance is thus an essential property of that capacity, featuring in the answer to "What is the human capacity to walk?', even though exercises can lack it. A walk with no wavering is thereby to that extent good. A walk in which uncontrollably flip head over feet and end up face down at the bottom of the stairs with appendages angled all over the place is in contrast thereby to that extent bad. The goodness or badness of an exercise thus depends on whether it has all, some, or none of the contingent essential properties of its genus and, if these properties come in degrees, to what degree it has them.

Generally, then, contingent essential properties explain why only certain things are by nature subject to standards and why those things are by nature subject to specific standards. The contingent essential properties of a genus are the properties whose possession or lack thereof determine whether the particular is good. If a genus has contingent essential properties, then, its particulars are by nature subject to a standard with respect to those very properties. If a genus does not, its particulars are not by nature subject to a standard. That is how contingent essential properties explain why only certain things are by nature subject to standards and why those things are by nature subject to specific standards.

\section{The nature of normativity}

In this section, I explain the account of normativity which follows from that answer to the central question of this essay. I will here introduce the language of internal and external

18. This view might seem to imply that to use a part of my body in a way which does not correspond with the standard to which it is by nature subject is to err. For example, if legs are for walking, perhaps I should not put mine behind my head. However, this inference is illicit. The metaphysics says that the nature of the part establishes a standard for it. A claim that I must only use the part in a way which conforms with that standard does not follow. Just as you can use a fork in order to brush your hair even if doing so means that you cannot just then use it for eating, you can put your feet behind your head even if doing so means that you cannot just then walk. Just do not break the fork or leg. Still, a fork not fit for brushing is bad for use as a comb but not as what it is. It is bad with respect to what I will later call an external standard but not the standard to which it is by nature subject. Likewise for legs not so limber. A fork not fit for use in eating is bad as what it is. Likewise for legs unfit for walking. 
standards which I mentioned at the outset of the essay. I close by describing how external standards depend on internal ones so as to complete this account.

4.1 To be by nature subject to a standard, or subject to an internal standard, is to be a particular of a genus with contingent essential properties. Such a particular is subject to a standard with respect to those very properties. Put as a claim about normative properties, nature-first constitutivism claims that

$P$ is internally good to the extent that and because (1) $\Gamma$ are the contingent essential properties of genus $G$, (2) P is a particular of $G$, and (3) P possesses some of $\Gamma$ to some degree.

$P$ is internally bad to the extent that and because (1) $\Gamma$ are the contingent essential properties of genus $G$, (2) $P$ is a particular of $G$, and (3) $P$ lacks some of $\Gamma$ to some degree.

Put as a claim about inferences, nature-first constitutivism claims that the following are valid:

1. $\Gamma$ are the contingent essential properties of $G$.

2. $P$ is a particular of $G$ that possesses some of $\Gamma$ to some degree.

C. $P$ is thereby to that extent good.

1. $\Gamma$ are the contingent essential properties of $G$.

2. $P$ is a particular of $G$ that lacks some of $\Gamma$ to some degree.

C. $P$ is thereby to that extent bad.

One way to understand these explanations and inferences is to think of this view as in part a unique account of the grounds of normative properties. It says that a particular possesses a normative property in part because of its actual properties and in part because of the contingent essential properties of its genus. ${ }^{19}$ That is why a stemmed wine glass without a

19. Normative standards are thus what Selim Berker calls explanation-involving in that they "contain as part of their content a relation of explanation between the features they specify and the moral [or other normative] properties under their purview" (Berker [2018] \$1). They are not what he calls explanation-serving in that they are not "part of what explains why a given action [or other particular of a genus with contingent essential properties] has a given moral [or otherwise normative] property" (ibid.). That is to say that the standardswhich we formulate in philosophical reflection-are not part of what explains why something is good or bad. 
stem is broken whereas a stemless one without a stem is not. It is why a human being without sight is blind whereas a rock without sight is not. Normative properties are thus resultant properties. Particulars possess them, not genera, and particulars possess them to the extent that and because they possess or lack the contingent essential properties of their genera. The inferences, when sound, track these grounds of normative properties.

Nature-first constitutivism, though, is not just a claim about what grounds normative properties. It is also in part an account of the nature of those properties. To explain normative properties in this way is to treat badness of the model of privation and goodness on the model of perfection. 'Blind', 'broken', and so on in this way label the lack of a specific contingent essential properties and thus a specific type of privation. 'Sight', 'whole', and so on in this way label the possession of those specific contingent essential properties and thus a specific type of perfection.

4.2 That account only explains the grounds of normative properties codified in standards to which certain things are by nature subject. It is only an account of normative properties codified in internal standards:

Internal Standard When $P$ is subject to an internal standard, it is subject to that standard because it is a particular of genus $G$, with the contingent essential properties of $G$ determining the content of that standard. That particular is good to the extent that and because it possesses those properties, bad to the extent that and because it lacks them.

Not all standards are internal. Although the genus APPLE has contingent essential properties, whether an apple is good for me to eat is not settled by those properties and the actual properties of that particular apple. Still, it can be good or bad for that purpose. Although the genus FORK has contingent essential properties, whether a fork is good for use as a comb is not settled by those properties and the actual properties of that particular fork. Still, it can be good or bad for that purpose. Even though the genus POTASSIUM HYDROXIDE does not have contingent essential properties, it can be good or bad for the purpose of dissolving my body.

I will here explain how contingent essential properties also terminate metaphysical explanations of these normative properties. The account of the external standards is as

They instead codify the explanatory relations which hold between certain properties or facts and normative properties or facts. 
follows:

External Standard When $P$ is subject to an external standard, it is subject to that standard because it is being used by an organism in an exercise of a capacity, with the contingent essential properties of that capacity determining the content of the standard. That particular is good to the extent that and because is contributes to the exercise possessing the contingent essential properties of that capacity, bad to the extent that and because it detracts from the exercise having those properties.

Let me explain.

Organisms use things and stuff. Fitness for this use is an external standard for something. One rock might make a good doorstop whereas another might not given differences in their shape and size. Although we make use of these things, though, we do not make them for that use. That use is thus not part of their essence in the way that the purpose for which we create an artificial kind is part of the essence of that kind. Rather than bottom out in the essential properties of the genus ROCK, the metaphysical explanation of why this rock is good for use as a doorstop bottoms out in the contingent essential properties of my capacity to prop open doors. That exercise of that capacity succeeds only if something stops the door from closing. This rock rather than that one is fit for that use because it has the needed heft and friction.

There is nothing unique about the fact that it is something inanimate being used here or, for that matter, about the fact that a human being rather than another organism uses it. Anything which any organism uses for any purpose is subject to an external standard. I can use a chair in order to access a cookie jar at a height beyond my reach. Tall and stable enough and it is to good to the extent that and because it contributes to the goodness of the exercise. Too short or unstable and it is bad to the extent that and because it contributes to the badness of the exercise. Similarly, my cat can eat a courgette, and it is good to the extent that and because it contributes to the goodness of his exercise of his capacity to digest, bad to the extent that and because it contributes to the badness of that exercise.

In general, then, something, whether an organism, a token of an artificial kind, or inanimate natural stuff is subject to an external standard when an organism uses it. That thing is good to the extent that and because it contributes to the goodness of that exercise, bad to the extent that and because it contributes to the badness of the exercise. Since the goodness or badness of an exercise of a capacity depends on the extent to which it possesses the 
contingent essential properties of that capacity, contingent essential properties are part of the metaphysical explanation of external goodness and badness.

$P$ is externally good to the extent that and because (1) $\Gamma$ are the contingent essential properties of the capacity to $A$, (2) $S$ uses $P$ in an exercise of the capacity to $A$, and (3) that exercise possesses some of $\Gamma$, or possesses them to a greater degree, in part because of the use of $P$ in it.

$P$ is externally bad to the extent that and because (1) $\Gamma$ are the contingent essential properties of the capacity to $A$, (2) $S$ uses $P$ in an exercise of the capacity to $A$, and (3) that exercise lacks some of $\Gamma$, or possesses them to a lesser degree, in part because of the use of $P$ in it.

In this way, explanations of all normative properties, internal and external alike, bottom out in contingent essential properties, though the explanations of external normative properties are a bit more involved. That is how nature-first constitutivism explains all normative properties.

\section{The rough ground ahead}

So ends my attempt to explain the basic metaphysics of the nature-first constitutivism behind some of the ambitious constitutivist projects in practical philosophy. I do not here claim that this view is correct. I instead only claim that it is a path worth trying, though one that needs to be cleared thoroughly in order to see the route and destination. This essay is part of that ground clearing, an attempt to articulate the basic structure and promise of this view.

What something is determines what it should be, then, if and only if and because the relevant genus has contingent essential properties. That is why only certain things are by nature subject to standards, and it is why those things are by nature subject to specific standards. This view grounds an account of internal goodness and badness as resultant properties which something possesses to the extent that and because it is a particular which possess or lacks the contingent essential properties of its genus. It grounds an account of external goodness and badness as resultant properties which something possesses to the extent that and because an organism uses it in the exercise of a capacity which possesses or lacks the contingent essential properties of that capacity at least in part because of the use of that thing. The view thus offers an account of all normative properties which unifies them in 
an intelligible grounded system without denying their diversity. That is a tidy explanatory package and a strong argument for trekking further along the rough ground of this trail.

Finally, let me say something about the relationship between this general metaphysics of nature-first constitutivism and the specific constitutivist metaphysics of human agency on which most discussions of constitutivism focus. The metaphysics of human agency is a specific determination of this general metaphysics of constitutivist genera or, what is the same thing, genera with contingent essential properties. It embodies that general explanatory structure. There is no inference, though, from the general metaphysics of such genera to the specific metaphysics of human agency anymore than there is an inference from the general metaphysics to the specific metaphysics of feline digestion. There cannot be insofar as all of the specific determination embody the general explanatory structure and yet they differ from each other in terms of the content of the description of the different genera and thus of the standards for the particulars of those genera. To understand our agency and the standards for its exercise, then, we must investigate our nature as we must in order to understand human digestion and the standard for its exercise. We must investigate human nature as we must investigate feline nature in order to understand cats and the standards for all of what they do. Ethical inquiry is in the sense an investigation into our essence.

\section{BIBLIOGRAPHY}

Aristotle, Metaphysics, translated by W.D. Ross and revised by Jonathan Barnes, in Jonathan Barnes (ed.) [1984], The Complete Works of Aristotle Volume 2, Princeton University Press, 1552-1728.

Jeremy Bentham [1789], An Introduction to the Principles of Morals and Legislation, edited by J.H. Burns and H.L.A. Hart [1970], Oxford University Press.

Matthew Boyle [2012], "Essentially Rational Animals", in Abel Guenther and James Conant (eds.) [2012], Rethinking Epistemology, Walter de Grutyer, 395-427.

Shamik Dasgupta [2016], "Metaphysical Rationalism", Nous 50:2, 379-418.

Cian Dorr [2016], "To Be F is To Be G", Philosophical Perspectives, 30, 39-134.

Luca Ferrero [2009], "Constitutivism and Inescapability", in Russ Shafer-Landau (ed.), Oxford Studies in Metaethics Vol. 4, Oxford University Press, 303-33.

Kit Fine [1994], "Essence and Modality", Philosophical Perspectives 8, 1-16.

Kit Fine [1995a], "Sense of Essence", in Walter Sinnott-Armstrong, Diana Raffman, and 
Nicholas Asher (eds.) [1995], Modality, Morality, and Belief: Essays in Honor of Ruth Barcan Marcus, Cambridge University Press, 53-73.

Kit Fine [1995b], "The Logic of Essence", Journal of Philosophical Logic 24(3), 241-73.

Jeremy David Fix $\left[\mathrm{ms}_{\mathrm{a}}\right]$, "The Error Condition".

Jeremy David Fix [ms $]$, "The Instrumental Rule".

Immanuel Kant [1781/7], Critique of Pure Reason, trans. by Allen Wood and Paul Guyer [1998], Cambridge University Press.

Immanuel Kant [1790], Critique of Judgment, trans. by Werner Pluhar [1987], Hackett Publishing.

Paul Katsafanas [2013], Agency and the Foundations of Ethics, Oxford University Press.

Christine M. Korsgaard [1998], "The Normativity of Instrumental Reason", reprinted in Christine M. Korsgaard [2008], The Constitution of Agency, Oxford University Press, 27-68.

Christine M. Korsgaard [2009], Self-Constitution, Oxford University Press.

Christine M. Korsgaard [2018], Fellow Creatures, Oxford University Press.

Christine M. Korsgaard [2019], "Constitutivism and the Virtues", Philosophical Explorations, Vol. 22 Iss. 2, 98-116.

Douglas Lavin [2004], "Practical Reason and the Possibility of Error", Ethics14 (3), 424-57.

Douglas Lavin [2017], "Forms of Rational Agency", Royal Institute of Philosophy Supplement 80, 171-93.

Gideon Rosen [2015], "Real Definition”, Analytic Philosophy, Vol. 56 No. 3, 189-209.

Karl Schafer [2019], "Constitutivism as Capacities-First Philosophy", Philosophical Explorations, Vol. 22, No. 2, 177-93.

Sergio Tenenbaum [2019], "Formalism and Constitutivism in Kantian Practical Philosophy", Philosophical Explorations, Vol 22, No. 2, 163-76.

Michael Thompson [2008], Life and Action, Harvard University Press. 